\title{
Performance and Statistical Comparison of the Expanded and Static Granular Sludge Bed Reactors Treating Poultry Slaughterhouse Wastewater
}

\author{
E. Kaskote, M. Basitere, S.K.O Ntwampe and M. Njoya
}

\begin{abstract}
Poultry slaughterhouse wastewater (PSW) is characterized by high organic pollutant levels. High rate anaerobic digesters are effective and economical in treating such effluent, removing pollutants at low cost. In this study, the performance of the static granular bed reactor (SGBR) and expanded granular sludge bed (EGSB), were compared. The bioreactors were used to treat PSW from the Western Cape, South Africa. Their performances were compared at hydraulic retention times (HRTs) of 55, 48 and $36 \mathrm{hrs,} \mathrm{and} \mathrm{organic}$ loading rates (OLRs) between 0.62 and $5.1 \mathrm{~g}-\mathrm{COD} / \mathrm{L} / \mathrm{day}$. The SGBR achieved an average COD removal of $78 \%$, while the EGSB achieved $66 \%$. The SGBR and EGSB's TSS removal efficiencies were $86 \%$ and $89 \%$, respectively. The SGBR's COD removal efficiencies at 55- and 36- hr HRTs were 70 and $87 \%$, respectively. Both were better than that of the EGSB at the same HRTs. At 48-hr HRT, however, there was minimal statistical difference in efficiency between them. There was no significant statistical difference between the two reactors in TSS removal efficiency at the various HRTs.
\end{abstract}

Keywords-Expanded Granular Sludge Bed Reactor; Hydraulic Retention Time, Organic loading rate; Static Granular Bed Reactor; Poultry Slaughterhouse Wastewater

\section{INTRODUCTION}

Recently in South Africa, the poultry industry has grown exponentially due to increasing demand. The growth continues and is associated with the consumption of large volumes of potable water for bird cleaning and processing. PSW is laden with organic matter originating from blood, meat trimmings, undigested food and feathers [6]. Potential environmental effects of the discharge of untreated PSW into surface water bodies are eutrophication [17] and groundwater contamination

Cape Peninsula University of Technology (CPUT) under URF RK16, Bioresource Engineering Research Group (BioERG) under RK45 and Thuthuka Funding (TTK180406318223).

E. kaskote is with the Department of Chemical Engineering, Faculty of Engineering and Built Environment, Cape Peninsula University of Technology, P.O. Box 1906, Bellville, South Africa, 7535 ()

M. Basitere is with the Department of Chemical Engineering, Faculty of Engineering and Built Environment, Cape Peninsula University of Technology, P.O. Box 1906, Bellville, South Africa, 7535

S.K.O. Ntwampe is with Department of Chemical Engineering and Bioresource Research Group, Cape Peninsula University of Technology, P.O. Box 1906, Bellville, South Africa, 7535
[20]. Chan et al. [4] and Rajakumar et al. [18] report that highly polluting industrial effluents can be treated using anaerobic systems, as their organic matter content is suitable and that this culminates in the production of biogas, an alternative energy source, with less sludge produced than from aerobic processes.

Numerous research studies have focused on the application of anaerobic digesters such as the expanded granular sludge bed (EGSB) and the static granular bed reactors (SGBR) to the treatment of PSW. The EGSB is a variant of the up-flow anaerobic sludge blanket (UASB) reactor, and is suitable for the treatment of low to high strength wastewaters, or those containing inert or poorly biodegradable organic matter that may accumulate in the biodigester. The SGBR is a simplified, high-rate, anaerobic granular system, developed to provide high performance efficiency while reducing bioreactor operating costs arising from design and/or fabrication complexity [10];[16]. Unlike the EGSB, which is operated in up-flow configuration, the SGBR is down-flow configured and relies on a granular biomass retained by an underdrain. The SGBR has lower energy requirements than the EGSB and has been shown to be able to treat PSW, with COD removal efficiency exceeding 95\% [6]. Working with an ESGB reactor, Núñez. and Martínez [14] reported that it achieved 67\% COD removal from PSW without a pre-treatment system. Cruz-Salomón et al. [5] obtained maximum COD removal efficiencies of 91,74 , and $96 \%$ when treating cheese whey, vinasse, and coffee processing wastewaters, respectively. A pilot-scale SGBR used by Roth [19] to treat pork slaughterhouse wastewater achieved COD removal efficiency exceeding 90\%. Similarly, Mach et al. [11] showed that an SGBR could treat sulphate-containing wastewater for more than a year with COD removal exceeding 90\%. Furthermore, Biese [3] used an SGBR to treat primary and secondary sludges and obtained a COD removal efficiency exceeding $90 \%$.

The main objective of this study was to compare the performance of the SGBR and EGSB reactors statistically in treating PSW, determine suitable treatment options under differing HRTs and OLRs. The analyses were used to elucidate the similarities and differences between the two reactor types. The SGBR is an innovative treatment process for low to medium strength wastewaters and is reported to yield an effluent containing low COD, VFA and TSS concentrations [10]. 


\section{MATERIALS AND METHODS}

\section{A. Inoculum And Wastewater Characteristics}

The PSW was collected from a poultry slaughterhouse in Cape Town, Western Cape Province, South Africa and refrigerated $\left(4^{\circ} \mathrm{C}\right)$ prior to experimental use. Both the SGBR and EGSB reactors were inoculated with granular sludge from a full-scale UASB treating brewery effluent at a South African brewery (SAB Miller Plc, Newlands, South Africa). A dry milk solution was introduced into the bioreactors as a carbon source for the anaerobic biomass and to facilitate the inoculum's acclimation. The dry milk solution contained $2000 \mathrm{mg}-\mathrm{COD} / \mathrm{L}$.

\section{B. Reactor Set-Up And Operation}

Two cylindrical glass reactors were constructed with identical working volumes $(2.33 \mathrm{~L})$ for the EGSB and SGBR (Fig. 1) reactors. The EGSB headspace comprised a phase separator to separate the product from the biogas and the flocculating sludge. Recirculation was used in the EGSB to control the reactor's water up-flow velocity, while pumice was used at the bottom as an underdrain and to assist - i.e., improve wastewater distribution.

The SGBR is broadly similar to the EGSB, but the influent enters at the top of the reactor through the inlet flow distribution system and flows downward by gravity through the bed of active anaerobic granules. The downflow operation allows the influent to be mixed with the bulk liquid by the counter-current flow of biogas and liquid. It was backwashed to remove suspended solids affecting the system when required - e.g., after clogging.

Influent was fed into the reactors using a multi-channel Gilson (Germany) peristaltic pump. The reactors operated at $40{ }^{\circ} \mathrm{C}$, which was maintained consistently by a water jacket and water bath system. A tedlar - polyvinyl fluoride - bag was connected to the top of each reactor to collect the biogas produced.

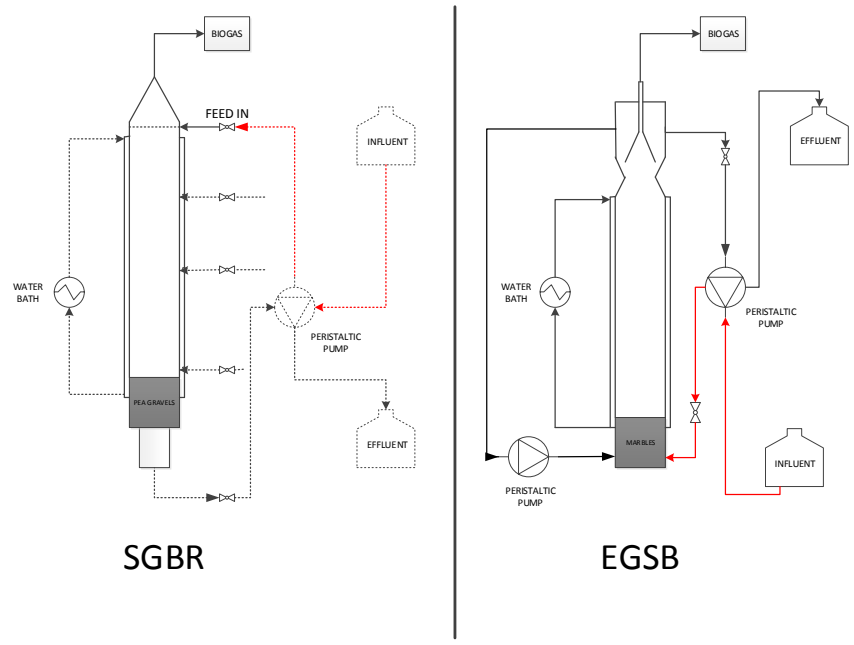

Fig. 1 Experimental set up

\section{Analytical Methods}

Total suspended solids (TSS) were measured using ESS method 340.2 [7]. Total dissolved solids (TDS) were determined with a PSCTestr 35 multi-parameter unit (Eutech Instruments). Turbidity was quantified with a Turbidimeter
TN-100 (Eutech Instruments). COD was determined using a Merck Spectroquant ${ }^{\circledR}$ NOVA 60 and Merck solutions A (1.14679.0495) and B (1.14680.0495). The results were verified by the City of Cape Town's Scientific Services Laboratory (Cape Town, South Africa) according to the American Public Health Association (APHA) standards [1].

\section{RESULTS AND DISCUSSION}

\section{A. Performance Capacity}

The performance capacity of the SGBR was compared to that of the EGSB at HRTs of 55, 48 and $36 \mathrm{hrs}$. The SGBR removed COD better at HRTs of 55 and $36 \mathrm{hrs}$, with average removals of $78 \%$ compared to $66 \%$ for the EGSB. No significant performance differences were observed between the SGBR and EGSB at 48-hrs HRT for either COD or TSS removal. The results also indicated that, at lower HRTs, ESGB performance decreased due to sludge wash-out arising from the increased flow rate.

TABLE I RESUlts Summary FoR THE SGBR AND EgSB

\begin{tabular}{|c|c|c|c|c|c|c|c|c|}
\hline \multirow{2}{*}{$\begin{array}{l}\text { Operating } \\
\text { period }\end{array}$} & \multirow{2}{*}{$\begin{array}{l}\text { HRT } \\
\text { (hours) }\end{array}$} & \multirow{2}{*}{$\begin{array}{l}\text { Parameter } \\
\text { (Units) }\end{array}$} & \multicolumn{3}{|c|}{ SGBR } & \multicolumn{3}{|c|}{ EGSB } \\
\hline & & & Influent & Effluent & $\begin{array}{c}\text { Efficiency } \\
(\%)\end{array}$ & Influent & Effluent & $\begin{array}{c}\text { Efficiency } \\
(\%)\end{array}$ \\
\hline \multirow{7}{*}{$\begin{array}{c}\text { Days } 0 \text { to } \\
40\end{array}$} & \multirow{7}{*}{55} & pH & 6.92 & 8.15 & NA & 6.87 & 6.87 & NA \\
\hline & & $\begin{array}{l}\text { COD } \\
(\mathrm{mg} / \mathrm{L})\end{array}$ & 2606 & 766 & 70 & 4221 & 1485 & 62 \\
\hline & & $\begin{array}{l}\text { TSS } \\
(\mathrm{mg} / \mathrm{L})\end{array}$ & 375 & 56 & 80 & 1123 & 62 & 93 \\
\hline & & $\begin{array}{l}\text { VSS } \\
(\mathrm{mg} / \mathrm{L})\end{array}$ & 658 & 391 & NA & 1325 & 416 & NA \\
\hline & & $\begin{array}{l}\text { Turbidity } \\
\text { (NTU) }\end{array}$ & 372 & 14 & 96 & 701 & 36 & 95 \\
\hline & & $\begin{array}{l}\mathbf{N O}_{3}-\mathbf{N} \\
(\mathrm{mg} / \mathrm{L})\end{array}$ & 0.54 & 3.52 & NA & 0.87 & 9.40 & NA \\
\hline & & $\begin{array}{l}\text { NH4-N } \\
(\mathrm{mg} / \mathrm{L})\end{array}$ & 110 & 170 & NA & 153 & 84 & NA \\
\hline \multirow{7}{*}{$\begin{array}{c}\text { Days } 40 \\
\text { to } 80\end{array}$} & \multirow{7}{*}{48} & pH & 6.90 & 7.69 & NA & 6.41 & 7.76 & NA \\
\hline & & $\begin{array}{l}\text { COD } \\
(\mathrm{mg} / \mathrm{L})\end{array}$ & 3871 & 821 & 77 & 7707 & 1285 & 81 \\
\hline & & $\begin{array}{l}\text { TSS } \\
(\mathrm{mg} / \mathrm{L})\end{array}$ & 1349 & 79 & 89 & 3447 & 233 & 92 \\
\hline & & $\begin{array}{l}\text { VSS } \\
(\mathrm{mg} / \mathrm{L})\end{array}$ & 2179 & 628 & NA & 22414 & 1145 & NA \\
\hline & & $\begin{array}{l}\text { Turbidity } \\
\text { (NTU) }\end{array}$ & 694 & 10 & 98.5 & 705 & 31 & 95.5 \\
\hline & & $\begin{array}{l}\mathrm{NO}_{3}-\mathbf{N} \\
(\mathrm{mg} / \mathrm{L})\end{array}$ & 2.70 & 16.91 & NA & 5.84 & 0.18 & NA \\
\hline & & $\begin{array}{l}\mathbf{N H}_{\mathbf{4}}-\mathbf{N} \\
(\mathrm{mg} / \mathrm{L})\end{array}$ & 193 & 192 & NA & 251 & 229 & NA \\
\hline \multirow{7}{*}{$\begin{array}{c}\text { Days } 80 \\
\text { to } 120\end{array}$} & \multirow{7}{*}{36} & pH & 6.49 & 7.62 & NA & 6.38 & 7.74 & NA \\
\hline & & $\begin{array}{l}\text { COD } \\
(\mathrm{mg} / \mathrm{L})\end{array}$ & 7155 & 788 & 87 & 7972 & 1585 & 79 \\
\hline & & $\begin{array}{l}\text { TSS } \\
(\mathrm{mg} / \mathrm{L})\end{array}$ & 2588 & 69 & 94 & 2098 & 292 & 71 \\
\hline & & $\begin{array}{l}\text { VSS } \\
(\mathrm{mg} / \mathrm{L})\end{array}$ & 3412 & 971 & NA & 869 & 1168 & NA \\
\hline & & $\begin{array}{l}\text { Turbidity } \\
\text { (NTU) }\end{array}$ & 858 & 7 & 99 & 743 & 65 & 91 \\
\hline & & $\begin{array}{l}\mathrm{NO}_{3}-\mathbf{N} \\
(\mathrm{mg} / \mathrm{L})\end{array}$ & 4.86 & 16.69 & NA & 2.88 & 0.87 & NA \\
\hline & & $\begin{array}{l}\mathbf{N H}_{4-N} \\
(\mathrm{mg} / \mathrm{L})\end{array}$ & 230 & 178 & NA & 199 & 203 & NA \\
\hline
\end{tabular}

\section{B. Organic Loading Rates}

The SGBR and the EGSB were operated continuously for 16 weeks at different HRTs and OLRs. COD and TSS were selected to compare reactor performance and monitor the effect of OLR throughout the study. During sludge acclimation, PSW diluted $50 \%$ with tap water and was fed to the reactors to avoid 
shock loading. Thereafter, influent strength was increased to $25 \%$ dilution and, later, the feed was undiluted. OLR variations in the SGBR and EGSB influents during the study are shown in Fig. 2.

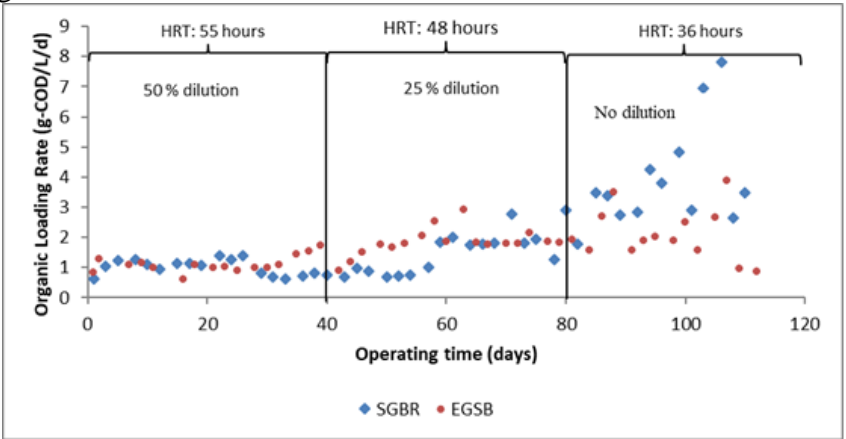

Fig. 2 Variation of Organic Loading Rate

OLR variations in the SGBR and EGSB influents during the study are shown in Fig 2. The OLR ranged from 0.62 to 5.32 $\mathrm{g}-\mathrm{COD} / \mathrm{L} / \mathrm{day}$ in both reactors. Influent COD concentrations in the same period ranged between $1,422.5$ and $11,708 \mathrm{mg} / \mathrm{L}$ for both reactors.

\section{SGBR, EGSB: COD Removal}

Fig. 3(a) and 3(b) illustrate the COD concentration and removal efficiencies of the two reactors at different HRTs $(\mathrm{n}=$ 3 ). In the first phase the HRT was 55 hrs, while, in the second and third phases, the HRTs were 48 and 36 hrs, respectively. The average COD removal efficiencies of the SGBR were 70, 77 and $87 \%$ during the three HRT phases, and those of the EGSB 62,81 and $79 \%$, respectively. The effluent COD concentrations from the reactors were similar despite the influent COD variation.

The EGSB's COD removal efficiency increased with increasing OLR concentration. This may be attributed to the ESGB's consistent effluent quality, even though the influent COD concentration was changing as the OLR increased, leading to higher COD removal efficiency. The quality of the effluent indicated the stability of the reactors. Furthermore, the anaerobic biomass responded better to environmental fluctuations and was suited to the ESGB's low influent flow rate. This was confirmed by Miranda et al. [12], who reported that an influent Oil and Grease/COD ratio above $20 \%$ is detrimental in full-scale UASBs, resulting in biomass washout and system failure.

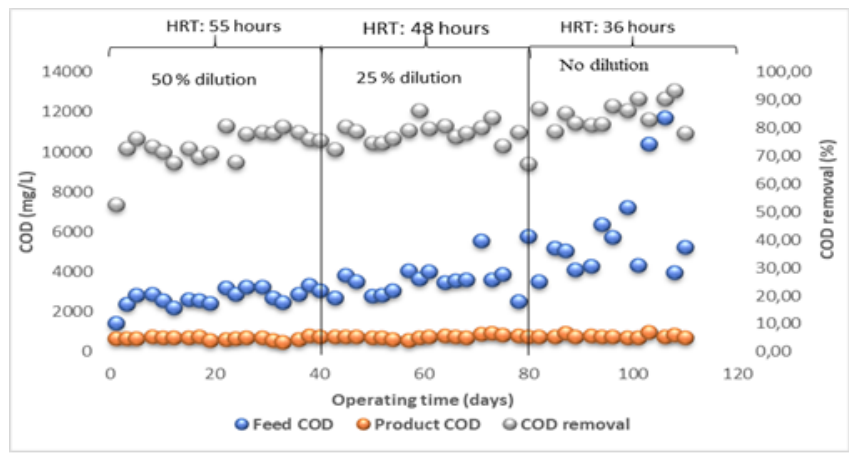

Figure 3(a) COD concentration and COD removal (\%) of the SGBR

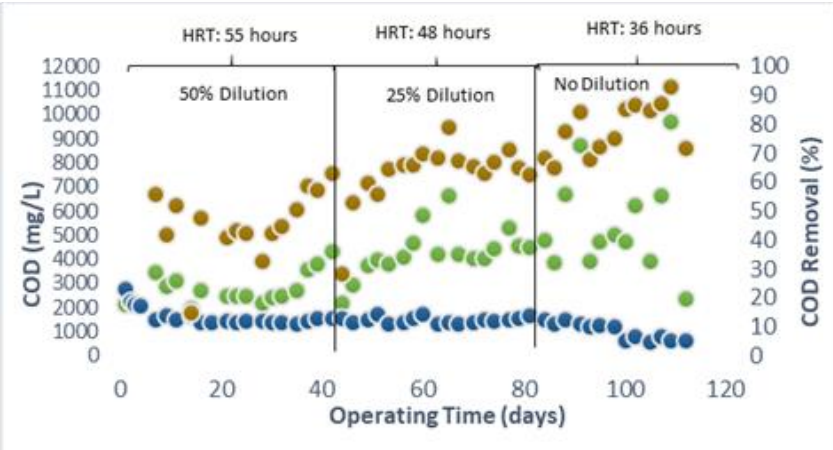

Fig 3(b) COD concentration and COD removal (\%) of the EGSB

\section{SGBR, EGSB: TSS Removal}

Fig. 4(a) and 4(b) show the TSS removal efficiencies of the two reactors. Both achieved high TSS efficiencies - between 71 and 94\% - during the trial, Oh et al. [16] reported TSS removal exceeding $80 \%$ for an SGBR treating dairy wastewater at ambient temperature, while Núñez. and Martínez [14] reported TSS removal of $90 \%$ treating slaughterhouse wastewater using an EGSB. Despite the variation in influent TSS concentration for the two reactors, they achieved consistent TSS removal. Basitere et al. [2] note that the SGBR's effluent TSS concentration depends on both the anaerobic digestion process and the physical processes retaining suspended solids in the granular bed, which acts as a biofilter. Because of this, the SGBR's down-flow operation contributes to TSS removal as the granular bed and pea gravel act as a filter.

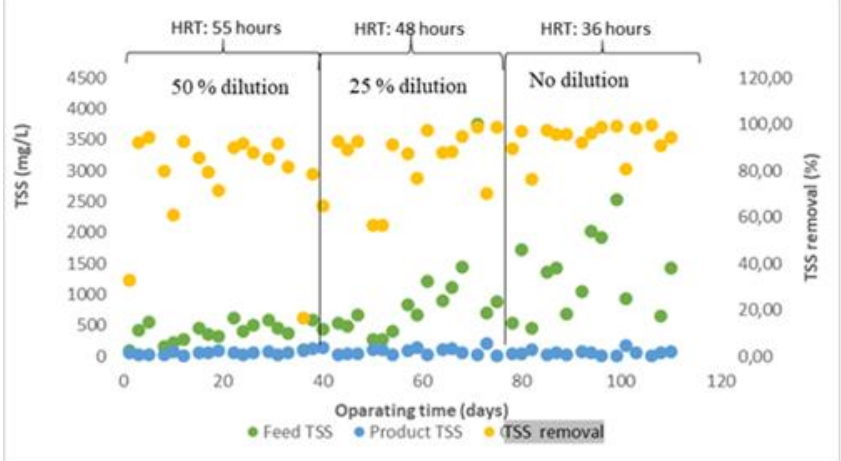

Figure 4(a) TSS and TSS removal (\%) of the SGBR

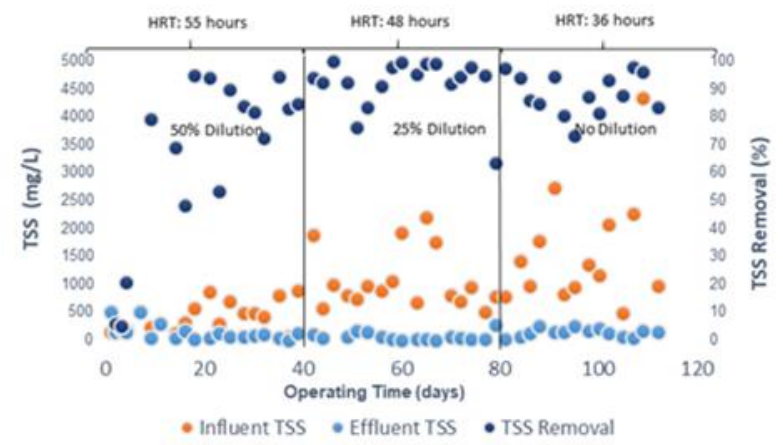

Figure 4(b) TSS and TSS removal (\%) of the EGSB

\section{E. Statistical Comparison Of SGBR And EGSB Reactor Performance}

Statistical analysis was used to establish the significance of 
the differences in performance of SGBR and EGSB, in COD and TSS removal efficiency at different HRTs. A paired T-test for means was used to determine whether the difference is genuine or could just have been chance. The test is generally used to compare pairs of means and determine whether they differ within a specified degree of certainty, the higher the $\mathrm{T}$-value, the more certain the differentiation of the systems compared.

TABLE II Statistical ANALysis For Cod ReMoval BETwEen SGBR AND EGSB

\begin{tabular}{c|cccc}
\hline HRT $($ hrs $)$ & Degrees of freedon & T-stat & T-critical & P-value \\
\hline 55 & 11 & 2.506 & 2.20 & 0.0292 \\
48 & 5 & 0.390 & 2.57 & 0.712 \\
36 & 5 & 5.954 & 2.57 & 0.00191 \\
\hline
\end{tabular}

TABLE III Statistical ANALysis For TsS Removal BetweEn SGBR AND EGSB

\begin{tabular}{c|clcc}
\hline HRT (hrs) & Degrees of freedom & T-stat & T-critical & $\boldsymbol{P}$-value \\
\hline 55 & 11 & -2.51 & 2.57 & 0.574 \\
48 & 5 & -0.6 & 2.57 & 0.574 \\
36 & 4 & 1.204 & 2.78 & 0.294 \\
\hline
\end{tabular}

At 55 hrs HRT for COD removal, the T-stat (2.506) exceeded the T-critical (2.20) - i.e., there was a real difference between the SGBR and EGSB means (see TABLE IV). As the p-value (0.0292) is less than 0.05 , the null hypothesis, that there is "minimal difference between the two means", could be rejected. Similar results were found at $36 \mathrm{hrs}$ HRT, but there is a difference between the SGBR and EGSB results at HRTs of 55 and 36 hrs. At $48 \mathrm{hrs}$ HRT, T-stat $(0.390)$ was below T-critical (2.57) and the P-value exceeded 0.05, in other words, the difference between the two means was insignificant.

The results of the parallel statistical analysis for TSS removal are shown in TABLE V . The P-value exceeded 0.05 for all three HRTs, meaning that there was insignificant differentiation in the reactors' TSS removal means or minimal TSS removal differentiation.

\section{CONCLUSION}

The SGBR's performance capacity was compared to that of ESGB at HRTs of 55, 48 and $36 \mathrm{hrs}$. The SGBR was shown to perform similarly to other high-rate anaerobic systems, and thus be potentially viable as a wastewater treatment alternative. Insignificant performance differences were observed between SGBR and EGSB, however, at 48 hrs HRT, for both COD and TSS removal. It was also found that, as the HRT decreased, ESGB performance decreased which minimized the PSW and granular sludge contact time. In general, the SGBR performed similarly to other high-rate anaerobic systems and is, therefore, a viable wastewater treatment option for the South African poultry industry.

\section{REFERENCES}

[1] APHA. WEF. 1998. Standard methods for the examination of water and wastewater. 1995;20.

[2] Basitere, M., Rinquest, Z., Njoya, M., Sheldon, M. and Ntwampe, S. 2017. Treatment of poultry slaughterhouse wastewater using a static granular bed reactor (SGBR) coupled with ultrafiltration (UF) membrane system. Water Science and Technology, 76(1), pp.106-114. https://doi.org/10.2166/wst.2017.179

[3] Biese, T. 2016. High rate anaerobic digestion of primary and secondary sludge using the static granular bed reactor (SGBR). Graduate Theses and Dissertations. Iowa State University, Ames, USA. Paper 15130. https://lib.dr.iastate.edu/etd/15130

[4] Chan, Y.J.; Chong, M.F.; Law, C.L.; Hassell, D.G. 2009. A review on anaerobic-aerobic treatment of industrial and municipal wastewater. Chemical Engineering Journal, p. 1-18. https://doi.org/10.1016/j.cej.2009.06.041

[5] Cruz-Salomón A., Ríos-Valdovinos E., Pola-Albores F., Meza-Gordillo R., Lagunas-Rivera S., Ruíz-Valdiviezo V.M. 2017. Anaerobic treatment of agro-industrial wastewaters for COD removal in expanded granular sludge bed bioreactor. Biofuel Research Journal 16. Pp 715-720. https://doi.org/10.18331/BRJ2017.4.4.3

[6] Debik, E. \& Coskun, T. 2009. Use of the Static Granular Bed Reactor (SGBR) with anaerobic sludge to treat poultry slaughterhouse wastewater and kinetic modeling. Bioresource Technology, 100: 2777-2782. https://doi.org/10.1016/j.biortech.2008.12.058

[7] ESS Method 340.2: Total Suspended Solids, Mass Balance (Dried at EC) Volatile Suspended Solids (Ignited at 550EC) Environmental Sciences Section Inorganic Chemistry Unit Wisconsin State Lab of Hygiene 465 Henry Mall Madison, WI Revised June 1993.

[8] Evans, E.A. and Ellis, T.G. 2005. Industrial Wastewater Treatment with the Static Granular Bed Reactor Versus the UASB. Proceedings of the Water Environment Federation 78th Annual Conference and Exposition, Washington, DC. https://doi.org/10.2175/193864705783867477

[9] Evans, E.A.; and Ellis, T.G. 2003. Performance Comparison of the UASB and Static Granular Bed Reactor. Proceedings Asian Waterqual 2003. IWA-Asia Pacific Regional Conference, Bangkok, Thailand.

[10] Mach, K.F. 2000. Development of Static Granular Bed reactor. M.S. thesis, Iowa State University, Ames, IA, USA.

[11] Mach, K.F.; Evans, E.A.; Roth, M.J.; and Ellis, T.G. 2003. Fundamentals of the Static Granular Bed Reactor. Proceedings Asian Waterqual 2003. IWA-Asia Pacific Regional Conference, Bangkok, Thailand.

[12] Miranda, L., Henriques, J. and Monteggia, L. 2005. A full-scale UASB reactor for treatment of pig and cattle slaughterhouse wastewater with a high oil and grease content. Brazilian Journal of Chemical Engineering, 22(4), pp.601-610. https://doi.org/10.1590/S0104-66322005000400013

[13] Mittal, G.S. 2004. Characterization of the Effluent Wastewater from Slaughterhouses for Land Application, Food Reviews International, 20:229-256. https://doi.org/10.1081/FRI-200029422

[14] Núñez, L. and Martínez, B. 1999. Anaerobic Treatment of Slaughterhouse Wastewater in an Expanded Granular Sludge Bed (EGSB) Reactor. Water Science and Technology, 40(8), pp.99-106. https://doi.org/10.2166/wst.1999.0396

[15] Oh, J. Performance evaluation of the pilot-scale static granular bed reactor (SGBR) for industrial wastewater treatment and biofilter treating septic tank effluent using recycled rubber particles. 2012. Graduate Theses and Dissertations. 12783.

[16] Oh, J., Park, J. and Ellis, T. 2014. Performance of on-site pilot static granular bed reactor (SGBR) for treating dairy processing wastewater and chemical oxygen demand balance modeling under different operational conditions. Bioprocess and Biosystems Engineering, 38(2), pp.353-363. https://doi.org/10.1007/s00449-014-1275-5

[17] Quinn, J.M. and Farlane, P.N. 1989. Effects of slaughterhouse and dairy factory wastewater on epilithon: A comparison in laboratory streams. Water Research, 23:1267-1273. https://doi.org/10.1016/0043-1354(89)90188-7

[18] Rajakumar, R.; Meenambal, T.; Saravanan, P.M.; Ananthanarayanan, P. 2012. Treatment of poultry slaughterhouse wastewater in hybrid upflow anaerobic sludge blanket reactor packed with pleated poly vinyl chloride rings. Bioresource Technology, Sausanne, v.103, p.116-122. https://doi.org/10.1016/j.biortech.2011.10.030

[19] Roth, M., Isik, F., Row, D. and Ellis, T. (2004). ON-SITE PILOT DEMONSTRATION OF THE STATIC GRANULAR BED REACTOR (SGBR). Proceedings of the Water Environment Federation, 2004(10), pp.207-232. https://doi.org/10.2175/193864704784131527

[20] Sangodoyin, A.Y. and Agbawhe, O.M. 1992. Environmental study on surface and groundwater pollutants from abattoir effluents. Bioresource 
Technology, 41:193-200.

https://doi.org/10.1016/0960-8524(92)90001-E

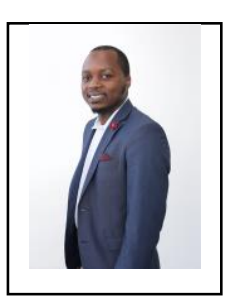

E. Kaskote received his BTech degree in Chemical Engineering from the Cape Peninsula University of Technology, Cape Town, South Africa in 2017. He is currently a process Engineer at Malutsa (Pty) Ltd; where he is involved in the design, costing and manufacturing of commercial and industrial water purification systems. 